\title{
An Investigation of Thermal Air Degradation and Pyrolysis of Per- and Polyfluoroalkyl Substances and Aqueous Film-Forming Foams in Soil
}

\author{
Ali Alinezhad $\$$, Pavankumar Challa Sasi ${ }^{\S}$, Ping Zhang\#, Bin Yao ${ }^{\S, \dagger}$, Svetlana A. Golovko*, Mikhail \\ Y. Golovko*, Alena Kubátová ${ }^{\prime}$, Feng Xiaos,* \\ \$Department of Civil Engineering, University of North Dakota, 243 Centennial Drive Stop 8115, Grand \\ Forks, North Dakota 58202, United States \\ \#School of Resources Environmental and Chemical Engineering, Nanchang University, Nanchang, \\ 330031, PR China \\ †Department of Chemistry, University of North Dakota, 151 Cornell Street Stop 9024, Grand Forks, \\ North Dakota 58202, United States \\ :Department of Biomedical Sciences, University of North Dakota, 1301 Columbia Road North Stop 9037, \\ Grand Forks, North Dakota 58202, United States
}

Number of pages: 20

Number of tables: 3

Number of figures: 18 


\section{Table of Contents}

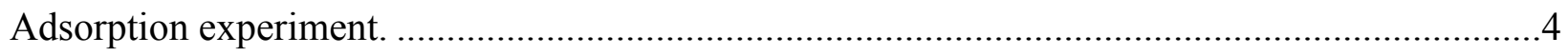

Treatment of soil particles laden with PFAS (Scenario \#1) . .....................................................

Scenario \#2: Thermal Decomposition of PFAS Loosely Associated with Soil. ...............................5

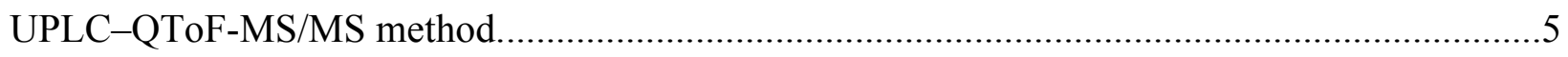

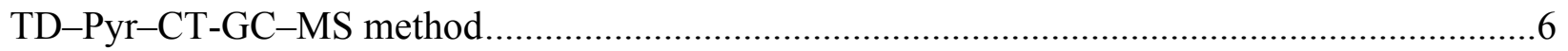

QA/QC

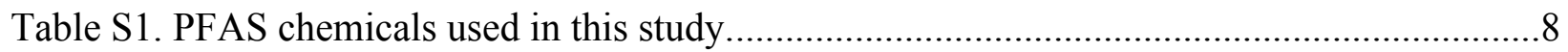

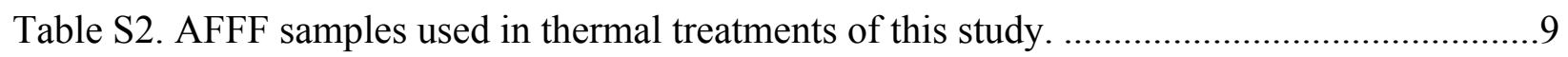

Table S3. Possible pyrolysis products of PFOA and PFOS detected in this study.......................10

Figure S1. Experimental schematic diagram......................................................................1

Figure S2. Recovery of PFCAs, PFSAs, and PFECA (i.e., HFPO-DA) from soil using methanol added with $100 \mathrm{mmol} / \mathrm{L}$ ammonium acetate. .......................................................................

Figure S3. Decomposition of PFOA and PFOS pre-adsorbed in a natural soil after thermally treated for $30 \mathrm{~min}$ at different temperatures under different atmospheres. The heating experiments were performed in a tube furnace under a flow of $\mathrm{N}_{2}$ and in a closed system with air.........................12

Figure S4. Temperature effect on 30-min thermal decomposition of zwitterionic (PFOSB and PFOAB) and cationic (PFOSAmS and PFOAAmS) along with $0.2 \mathrm{~g}$ of clay (Scenario 2).........12

Figure S5. Decomposition of PFSAs and polyfluoroalkyl substances present in AFFF (see Table

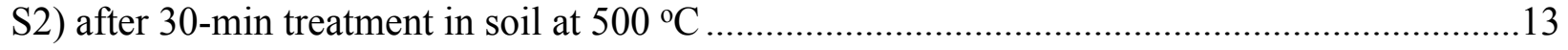

Figure S6. Effect of soil texture on thermal decomposition of PFOA. ......................................13

Figure S7. Apparent yield of F from PFOA (initial mass: $1 \mu \mathrm{mol}$ ) heated for $30 \mathrm{~min}$ at different temperatures with or without the presence of a dried natural soil $(0.2 \mathrm{~g})$..................................14

Figure S8. XRD spectra of raw kaolinite $(0.6 \mathrm{~g})$ and a mixture of kaolinite and PFOA (0.005 g) after 30-min thermal treatments at different temperatures.

Figure S9. FTIR spectra of non-heated kaolinite, non-heated PFOA powers, and a mixture of kaolinite $(0.2 \mathrm{~g})$ and PFOA $\left(1.2 \times 10^{-5}-1.2 \times 10^{-4} \mathrm{~mol}\right)$ after 30 -min thermal treatment at $400{ }^{\circ} \mathrm{C}$.

Figure S10. Possible formation pathways of perfluoroalkenes and perfluoroalkanes from PFAS during heating.

Figure S11. TD-Pyr-CT-GC-MS spectrum of perfluoro-1-heptene (CAS: 755-25-9) generated after heating PFOA at $200^{\circ} \mathrm{C}$.

Figure S12. TD-Pyr-CT-GC-MS spectrum of hexane, 1,1,1,2,2,3,3,4,4,5,5,6,6-tridecafluoro(CAS: 355-37-3) generated after heating PFOA at $200^{\circ} \mathrm{C}$.

Figure S13. TD-Pyr-CT-GC-MS spectrum of perfluoro-1-heptene (CAS: 755-25-9) generated after heating PFOA at $300{ }^{\circ} \mathrm{C}$. 
Figure S14. TD-Pyr-CT-GC-MS spectrum of perfluoro-1-heptene (CAS: 755-25-9) generated

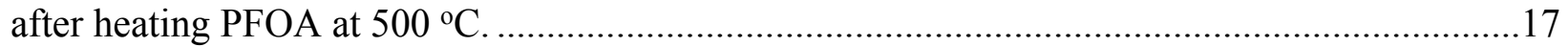

Figure S15. TD-Pyr-CT-GC-MS spectrum of hexane, 1,1,1,2,2,3,3,4,4,5,5,6,6-tridecafluoro(CAS: 355-37-3) generated after heating PFOA at $890{ }^{\circ} \mathrm{C}$.

Figure S16. TD-Pyr-CT-GC-MS spectrum of perfluoro-1-heptene (CAS: 755-25-9) generated after heating PFOS at $500{ }^{\circ} \mathrm{C}$. 18

Figure S17. TD-Pyr-CT-GC-MS spectrum of perfluorooctane (CAS: 307-34-6) generated after heating PFOS at $500{ }^{\circ} \mathrm{C}$.

Figure S18. TD-Pyr-CT-GC-MS spectrum of heptane, hexadecafluoro- (CAS: 335-57-9)

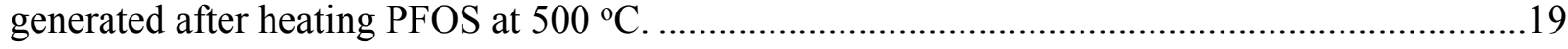

References cited in the Supporting Information. .20 


\section{Adsorption experiment.}

The liquid phase was a landfill leachate sample provided by the Waste Management Inc. that was spiked with PFAS to $\sim 2 \times 10^{-6} \mathrm{~mol} / \mathrm{L}$ in the laboratory to facilitate the detection. Sorption experiments were conducted in 50-mL Thermo Scientific Nunc ${ }^{\mathrm{TM}}$ sterile polypropylene test vials that were rotated end-over-end at $40 \mathrm{rpm}$ and $\sim 22{ }^{\circ} \mathrm{C}$ for two days. The apparent sorption equilibrium reached in two days. After sorption, a test vial was centrifuged, and an aliquot of 3 $\mathrm{mL}$ of the aqueous phase was sampled and microfiltered $(0.45 \mu \mathrm{m}$ nylon filter; Thermo Scientific Target2) for determination of the residual aqueous concentrations of PFAS $\left(C_{\mathrm{w}}\right)$. Sorbent-free controls were prepared and spiked with a PFAS at the same initial dose as in the corresponding test vials. These control samples were manipulated in the same manner as test samples. The sorbed level $\left(C_{\mathrm{s}}, \mu \mathrm{mol} / \mathrm{kg}\right)$ was computed by subtracting the concentration in the test vial $\left(C_{\mathrm{w}}, \mu \mathrm{mol} / \mathrm{L}\right)$ from that in the corresponding control vial and then normalizing for the soil mass in the test vial.

\section{Treatment of soil particles laden with PFAS (Scenario \#1).}

Soil particles laden with PFAS were split into two portions. One portion of the particles was extracted using methanol $\left(V_{\text {extr }}, \mathrm{mL}\right)$ added with ammonium acetate at $100 \mathrm{~mol} / \mathrm{L}^{1}$ to determine the PFAS mass before thermal treatment $\left(M_{\mathrm{PFAS}, \text { solid,initial }}\right)$ using eq s4:

$$
M_{\mathrm{PFAS} \text {,solid,initial }}=\left(C_{\text {extr }} \times V_{\text {extr }}\right) / E
$$

where $E(\%)$ is the extraction efficiency and $C_{\text {extr }}(\mu \mathrm{mol})$ is the concentration of PFAS in the extract measured using a Waters Acuity ultrahigh-pressure liquid chromatograph coupled with a Waters QToF-MS/MS (Synapt G2-S, Waters Corporation, Milford, MA, USA). ${ }^{2,3}$ Analytical details are described in the SI. Our extraction method achieved recoveries of $90.2 \%-104.2 \%$ for PFAS from soil (Figure $\mathrm{S} 2$ ). The limits of detection $(\mathrm{S} / \mathrm{N}=3)$ are $7 \mathrm{nmol} / \mathrm{L}$ for PFBA and PFPeA, $2 \mathrm{nmol} / \mathrm{L}$ for PFSAs, $5 \mathrm{nmol} / \mathrm{L}$ for other anionic PFAS, and $5 \mathrm{nmol} / \mathrm{L}$ for cationic and zwitterionic PFAS. The other portion of the PFAS-laden solid particles $(0.2 \mathrm{~g})$ was placed in a pre-cleaned, borosilicate biochemical oxygen demand (BOD) bottle with glass pennyhead stoppers (henceforth referred as container) $^{1}$ and heated within a muffle furnace (Neytech., Vulcan 3-550, USA) at a preset temperature. We previously found that the borosilicate glass has no effect on the thermal decomposition of PFOA. ${ }^{4}$

After heat treatment and cooldown, the container was added with DW to measure waterextractable fluoride ions $\left(\mathrm{F}^{-}\right)$or methanol (amended with $100 \mathrm{mmol} / \mathrm{L}$ ammonium acetate) to measure residual PFAS (see SI). ${ }^{1}$ The solution was sonicated for $30 \mathrm{~min}$ in an ultrasonic cleaner (frequency: $40 \mathrm{KHz}$ ). In a separate experiment, no degradation of PFAS was observed as a result of sonication by this low-frequency ultrasonic cleaner. After sonication, the DW or methanol solution was microfiltered $(0.45 \mu \mathrm{m}$ nitrocellulose membrane, Whatman). Concentrations of fluoride ions $\left(\mathrm{F}^{-}\right)$in the aqueous solution and residual PFAS in methanol samples were determined, ${ }^{1}$ and their masses $\left(M_{\mathrm{F}}\right.$ and $\left.M_{\mathrm{PFAS}, \text { residual }}, \mu \mathrm{mol}\right)$ were calculated in the manner described previously. ${ }^{1}$ Concentrations of $\mathrm{F}^{-}$were determined by the USEPA SPADNS method ${ }^{5}$ and a $\mathrm{F}$ ion selective electrode (F-ISE) coupled with a $\mathrm{pH} / \mathrm{mV}$ meter (FiveEasy ${ }^{\mathrm{TM}}$, Mettler Toledo, Ohio, USA). The thermal decomposition efficiency was calculated by comparing the residual mass of PFAS in heated samples $\left(M_{\mathrm{PFAS}, \text { residual, }} \mu \mathrm{mol}\right)$ with that in the non-heated controls $\left(M_{\mathrm{PFAS} \text {,initial, }}\right.$ $\mu \mathrm{mol})$.

The yield of F from a PFAS with $(2 n+1) \mathrm{F}$ atoms during thermal treatments was calculated with the following equation:

$$
\text { Yield }(\mathrm{F})=\frac{M_{\mathrm{F}}}{(2 n+1)\left[M_{\mathrm{PFAS}, \text { initial }}-M_{\mathrm{PFAS}, \text { residual }}\right]} \times 100 \%
$$




\section{Scenario \#2: Thermal Decomposition of PFAS Loosely Associated with Soil.}

For the second scenario, experiments were performed by directly mixing PFAS chemicals or AFFF with soil particles to represent the free state of PFAS molecules in soil or those weakly associated with soil.

In the case of AFFF, a known volume of AFFF stock solution in methanol was added to the soil in a container. The AFFF-spiked soil was manually mixed with a sterile plastic L-shaped spreader (FisherBrand ${ }^{\circledR}$ ) in a fume hood, subsequently freeze-dried, and stored in a desiccator to reach room temperature. Soil particles laden with AFFF were split into two portions. One portion of the particles was extracted to determine PFAS mass before thermal treatment. The other portion of AFFF-laden soil particles was thermally treated and subsequently extracted in the manner as described above.

\section{UPLC-QToF-MS/MS method.}

The analysis was carried out on a Waters Acquity ultrahigh pressure liquid chromatography (UPLC) system coupled with a Waters QToF-MS/MS² (Synapt G2-S, Waters Corporation, Milford, MA, USA) available in the Department of Biomedical Sciences of University of North Dakota. Chromatography was performed using a Waters Acquity UPLC BEH Shield RP18 column $(100 \times 2.1 \mathrm{~mm} ; 130 \AA ; 1.7 \mu \mathrm{m})$ with a Waters Acquity UPLC BEH Shield RP18 VanGuard precolumn $(5 \times 2.1 \mathrm{~mm} ; 130 \AA \AA 1.7 \mu \mathrm{m})$. The mobile phase consisted of eluent $\mathrm{A}(2 \mathrm{mM}$ ammonium formate in Optima ${ }^{\mathrm{TM}}$ water; LC/MS grade) and eluent $\mathrm{B}\left(2 \mathrm{mM}\right.$ ammonium formate in Optima ${ }^{\mathrm{TM}}$ methanol; LC/MS grade). The elution started at $20 \% \mathrm{~B}$ for $0.5 \mathrm{~min}$ and then was linearly increased to $85 \% \mathrm{~B}$ in $5 \mathrm{~min}$, further increased to $98 \% \mathrm{~B}$ in $0.1 \mathrm{~min}$ and kept isocratic for $1.5 \mathrm{~min}$. At 7.1 min, the $\mathrm{A} / \mathrm{B}$ ratio changed back to the initial value of $80 / 20$ over $0.1 \mathrm{~min}$ to re-equilibrate the column for another $1.3 \mathrm{~min}$. Analytes were eluted using a Waters Acquity UPLC pump equipped with a well-plate autosampler that was maintained at $8{ }^{\circ} \mathrm{C}$. The flow rate was maintained at 0.45 $\mathrm{mL} / \mathrm{min}$, and the column temperature was $55^{\circ} \mathrm{C}$.

Mass spectrometry analysis was performed using the Synapt G2-S QToF-MS with an ESI source operated in a negative or positive ion mode. MS operating conditions were as follows: cone voltage, $20 \mathrm{~V}$; capillary voltage, $1.8 \mathrm{kV}$; source temperature, $110{ }^{\circ} \mathrm{C}$; desolvation temperature, 350 ${ }^{\circ} \mathrm{C}$; cone gas flow rate, $10 \mathrm{~L} / \mathrm{h}$; and desolvation gas flow, $1,000 \mathrm{~L} / \mathrm{h}$. The analyzer was operated with an extended dynamic range at 10,000 resolution (fwhm at $\mathrm{m} / z$ 554) with an acquisition time of $0.1 \mathrm{~s}$. The Synapt G2-S ToF MS ${ }^{\mathrm{E}}$ mode was used to collect data with the T-wave element alternated between a low energy of $2 \mathrm{~V}(\mathrm{MS})$ and high energy $\left(\mathrm{MS}^{\mathrm{E}}\right)$ states in which the transfer T-wave element voltage ranged from $10-25 \mathrm{~V}$. Leucine enkephalin $(400 \mathrm{pg} / \mu \mathrm{L})$ was infused at a rate of $10 \mu \mathrm{L} / \mathrm{min}$ for mass correction. MassLynx V4.1 software (Waters) was used for instrument control, acquisition, and mass analysis. The structural information of the degradation products was obtained by the state-of-the-art MSE function that allows the simultaneous acquisition of both MS and MS/MS fragmentation during a single chromatographic run.,.$^{\mathbf{3 , 6}}$

Quantification of all target PFAAs were made using extracted ion currents (10 ppm mass window) and were based on their $\mathrm{m} / \mathrm{z}$ values and UPLC retention times relative to a six-point external calibration standard curves. 


\section{TD-Pyr-CT-GC-MS method}

The Frontier 3030D pyrolyzer is installed on top of the GC including optional autosampler. This system allows for multiple-step heating including TD at $\leq 300{ }^{\circ} \mathrm{C}$ (evolution of intact low MW compounds) and Pyr, typically at temperatures above $350{ }^{\circ} \mathrm{C}$ (evolution of thermal breakdown products of high MW species or thermally stable species). Following the different TDPyr steps, the gaseous products were concentrated in CT, and introduced on the GC column and analyzed by GC-MS. A Frontier 30-m Ultra Alloy capillary column (30 m; Frontier Labs Inc., Japan) was used with an inner diameter of $0.25 \mathrm{~mm}$ and a $5 \%$ diphenyldimethyl polysiloxane stationary phase with $0.25 \mu \mathrm{m}$ film thickness. below).

Four analyses at different temperatures were performed on each of the PFAS samples (see

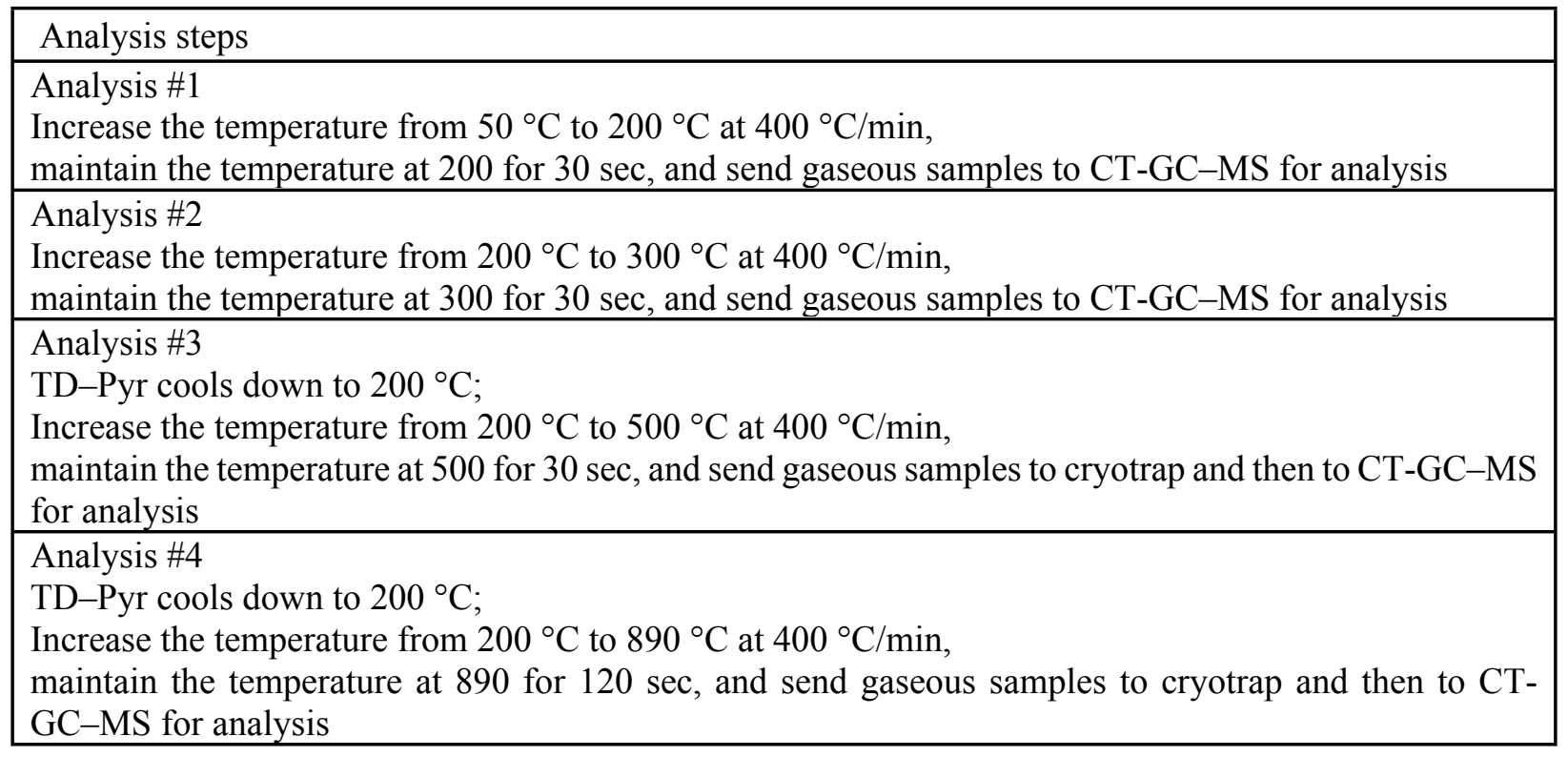

For each temperature the interface was opened for $2.5 \mathrm{~min}$ to transfer the analytes (products) through the heated transferline A GC injector port (in a 1:50 split) was kept at $300{ }^{\circ} \mathrm{C}$ until the column was steady at $40{ }^{\circ} \mathrm{C}$, after which a $\mathrm{GC}$ analysis was conducted. The $\mathrm{GC}$ temperature program started at $40^{\circ} \mathrm{C}$ for $1 \mathrm{~min}$ followed by a gradient of $40^{\circ} \mathrm{C} / \mathrm{min}$ to $80^{\circ} \mathrm{C}$, and then $25^{\circ} \mathrm{C} / \mathrm{min}$ to $320^{\circ} \mathrm{C}$, and held for $4 \mathrm{~min}$. The MS analysis was performed with electron ionization in the mass range of $35-850 \mathrm{~m} / \mathrm{z}$. Ultra-pure helium $(99.999 \%)$ was used as the carrier gas with a constant flow rate of $1.1 \mathrm{~mL} \mathrm{~min}^{-1}$.

\section{QA/QC.}

The closed containers were washed thoroughly with deionized (DI) water and methanol after every thermal treatment of soilborne PFAS. In randomly selected cleaned containers, we added $25 \mathrm{~mL}$ DI water and measured PFAS in the water; no measurable concentrations of target PFAS were found. 
Furthermore, unspiked controls were prepared in PFAS-free containers with only soil/kaolinite to examine possible contamination of samples by PFAS from laboratory apparatus. The control samples were treated in the procedures as described in the text. No measurable PFAS were found in these control samples. 
Table S1. PFAS chemicals used in this study.

\begin{tabular}{|c|c|c|c|c|}
\hline \multicolumn{5}{|c|}{ PFAS analyzed in the negative ESI mode } \\
\hline PFCAs & Acronyms & Purity & CAS & Structure \\
\hline Perfluorobutyric acid (C4) (a) & PFBA & $\geq 99.5$ & $375-22-4$ & FFF \\
\hline perfluoropentanoic acid (C5) (a) & PFPeA & $97 \%$ & $2706-90-3$ & \\
\hline Perfluoroheptanoic acid (C6) (b) & PFHpA & $\geq 98 \%$ & $375-85-9$ & \\
\hline Perfluorooctanoic acid (C8) (a) & PFOA & $95 \%$ & $335-67-1$ & \\
\hline Perfluorononanoic acid (C9) (a) & PFNA & $97 \%$ & $375-95-1$ & \\
\hline Perfluorodecanoic acid (C10) (a) & PFDA & $98 \%$ & $335-76-2$ & \\
\hline Perfluoroundecanoic acid (C11) (a) & PFUnDA & $95 \%$ & $2058-94-8$ & \\
\hline PFSAs & Acronyms & Purity & & Structure \\
\hline $\begin{array}{l}\text { Perfluorobutanesulfonic acid } \\
\text { potassium salt }(\mathrm{C} 4)(\mathrm{a})\end{array}$ & PFBS & $98.0 \%$ & $\begin{array}{c}29420-49- \\
3 \\
\end{array}$ & 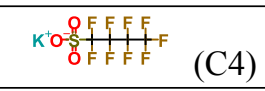 \\
\hline $\begin{array}{l}\text { Perfluorohexanesulfonic acid } \\
\text { potassium salt (C6) (a) }\end{array}$ & PFHxS & $\geq 98.0 \%$ & $3871-99-6$ & \\
\hline $\begin{array}{l}\text { Perfluorooctanesulfonic acid } \\
\text { potassium salt }(\mathrm{C} 8)(\mathrm{a})\end{array}$ & PFOS & $\geq 98.0 \%$ & $2795-39-3$ & \\
\hline \multicolumn{5}{|c|}{ Legacy anionic PFAS } \\
\hline $\begin{array}{c}2-(N- \\
\text { methylperfluorooctanesulfonamido) } \\
\text { acetic acid (c) }\end{array}$ & $\begin{array}{c}N- \\
\text { MeFOSAA }\end{array}$ & $\begin{array}{l}\text { Reference } \\
\text { standard }\end{array}$ & $2355-31-9$ & \\
\hline $\begin{array}{l}\text { 8:2 fluorotelomer sulfonic acid } \\
\text { sodium salt (c) }\end{array}$ & $8: 2$ FTS & $\begin{array}{l}\text { Reference } \\
\text { standard }\end{array}$ & & \\
\hline $\begin{array}{c}\text { PFECA } \\
\text { (perfluoroalkyl ether carboxylic } \\
\text { acid) }\end{array}$ & Acronym & Purity & & Structure \\
\hline $\begin{array}{l}\text { 2,3,3,3-tetrafluoro-2-(1,1,2,2,3,3,3- } \\
\text { heptafluoropropoxy)propanoic acid } \\
\text { (C3) (b) }\end{array}$ & HFPO-DA & $97 \%$ & $\begin{array}{c}13252-13- \\
6\end{array}$ & \\
\hline 6:2 Cl-PFAES & Acronym & Purity & & Structure \\
\hline $\begin{array}{l}\text { 6:2 chlorinated polyfluorinated ether } \\
\text { sulfonate potassium salt (c) }\end{array}$ & $\begin{array}{l}6: 2 \mathrm{Cl}- \\
\text { PFAES }\end{array}$ & $\begin{array}{l}\text { Reference } \\
\text { standard }\end{array}$ & & \\
\hline \multicolumn{5}{|c|}{ PFAS analyzed in the positive ESI mode } \\
\hline $\begin{array}{c}\text { Cationic and zwitterionic } \\
\text { compounds }\end{array}$ & Acronym & Purity & & Structure \\
\hline $\begin{array}{l}\text { Perfluorooctaneamido ammonium salt } \\
\text { (d) }\end{array}$ & PFOAAmS & $98 \%$ & $335-90-0$ & $\mathrm{~F}_{15} \mathrm{c}_{7} \mathrm{\gamma}^{\mathrm{H}}$ \\
\hline $\begin{array}{l}\text { Perfluorooctanesulfonamido } \\
\text { ammonium salt (d) }\end{array}$ & PFOSAmS & $98 \%$ & $1652-63-7$ & 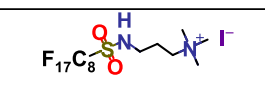 \\
\hline Perfluorooctaneamido betaine (d) & PFOAB & $95 \%$ & $\begin{array}{l}90179-39- \\
8\end{array}$ & $\mathrm{~F}_{15} \mathrm{c}_{7} \mathrm{O}_{\mathrm{N}}^{\mathrm{H}} \sim \mathrm{N}^{\mathrm{O}} \mathrm{g}^{\mathrm{OH}}$ \\
\hline $\begin{array}{l}\text { Perfluorooctanesulfonamido betaine } \\
\text { (d) }\end{array}$ & PFOSB & $95 \%$ & $\begin{array}{c}\text { 75046-16- } \\
1\end{array}$ & $\mathrm{~F}_{17} \mathrm{C}_{8}^{-\mathrm{H}} \mathrm{OH}^{\mathrm{H}} \mathrm{N} \mathrm{N}_{0} \mathrm{OH}$ \\
\hline
\end{tabular}

Providers: (a): Sigma-Aldrich; (b): Fisher Scientific; (c): Wellington Laboratories Inc.; (d) Fluobon Surfactant Institute (China) 
Table S2. AFFF samples used in thermal treatments of this study.

\begin{tabular}{|c|c|l|}
\hline Acronyms & Manufacturer & \multicolumn{1}{|c|}{ Manufacturing date } \\
\hline AFFF \#1 & $3 \mathrm{M}$ & May 1979 \\
\hline AFFF \#2 & $3 \mathrm{M}$ & March 1998 \\
\hline
\end{tabular}

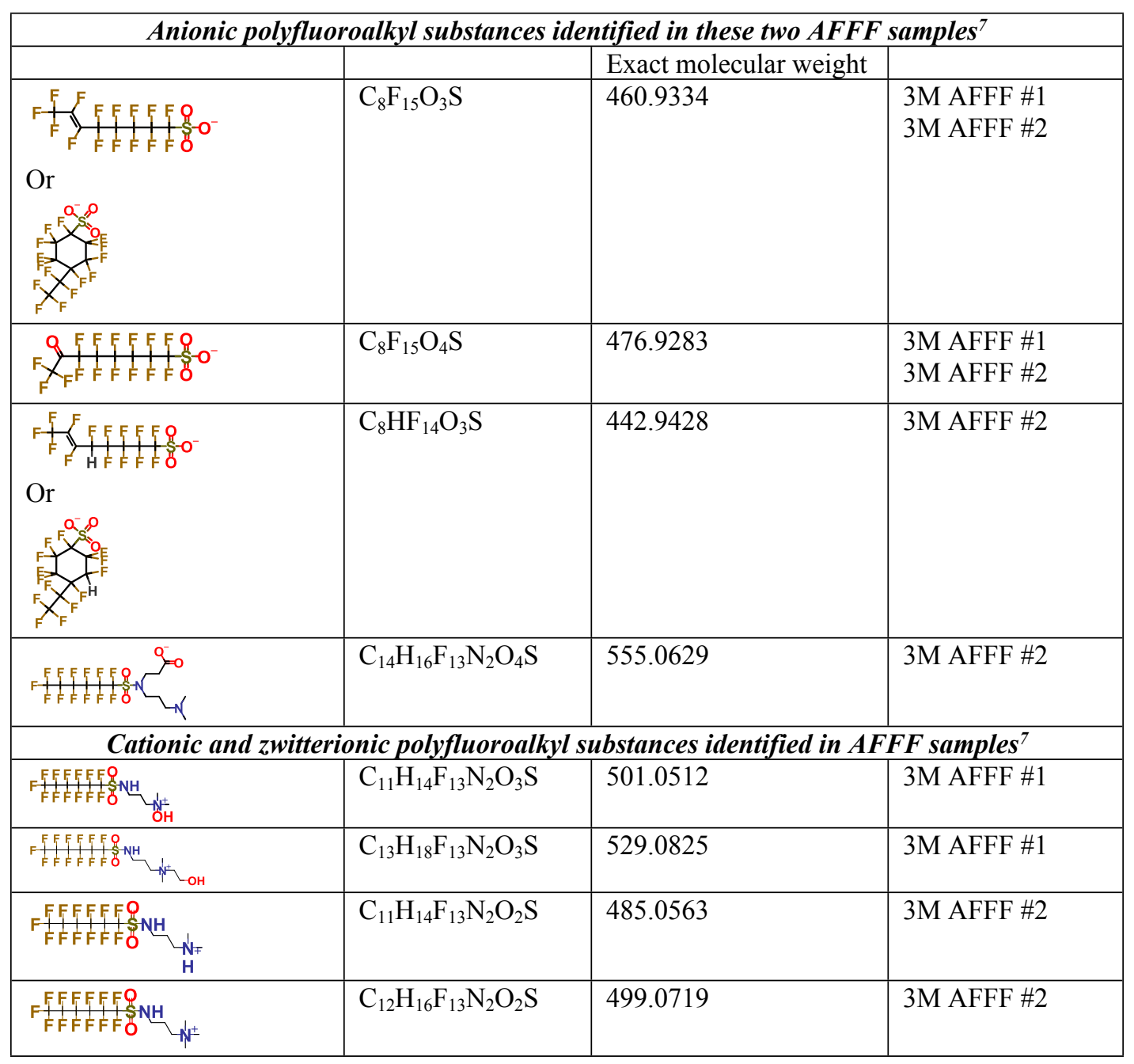


Table S3. Possible pyrolysis products of PFOA and PFOS detected in this study.

\begin{tabular}{|c|c|c|c|c|c|}
\hline CAS & $\begin{array}{c}\text { Molecular } \\
\text { Formula }\end{array}$ & Name & Chemical structure & $\begin{array}{c}\text { Molecular } \\
\text { weight }(\mathrm{g} / \mathrm{mol})\end{array}$ & $\begin{array}{c}\text { Identification (temperature } \\
\left.\left({ }^{\circ} \mathrm{C}\right) \text {; match quality }(\%)\right)\end{array}$ \\
\hline \multicolumn{6}{|c|}{ Perfluoroalkenes } \\
\hline $\begin{array}{l}00035 \\
5-63-5\end{array}$ & C7F14 & $\begin{array}{l}\text { Perfluoro-1- } \\
\text { heptene }\end{array}$ & & 350.05 & $\begin{array}{l}\text { PFOA }(200 ; 83), \text { PFOA }(300 ; \\
90), \text { PFOA }(500 ; 90), \text { PFOS } \\
(300 ; 43), \text { PFOS }(500 ; 86), \\
\text { PFOS }(500 ; 76), \text { PFOS }(890 ; \\
50)\end{array}$ \\
\hline $\begin{array}{l}00035 \\
5-37-3\end{array}$ & C6HF13 & $\begin{array}{l}\text { Hexane, } \\
1,1,1,2,2,3,3,4 \\
, 4,5,5,6,6- \\
\text { tridecafluoro- }\end{array}$ & & 320.05 & $\begin{array}{l}\text { PFOA }(200 ; 78), \text { PFOA }(300 ; \\
59), \text { PFOA }(500 ; 64), \text { PFOA } \\
(890 ; 78)\end{array}$ \\
\hline $\begin{array}{l}00075 \\
5-25-9\end{array}$ & C6F12 & $\begin{array}{l}\text { perfluoro-1- } \\
\text { hexene }\end{array}$ & & 300.05 & $\begin{array}{l}\text { PFOA }(200 ; 42), \text { PFOS }(300 ; \\
59), \text { PFOS }(500 ; 64), \text { PFOS } \\
(890 ; 45)\end{array}$ \\
\hline $\begin{array}{l}00011 \\
6-15-4\end{array}$ & C3F6 & $\begin{array}{l}\text { Propene, } \\
\text { hexafluoro- }\end{array}$ & & 150.02 & $\begin{array}{l}\text { PFOS (300; 10), PFOS (500; } \\
59)\end{array}$ \\
\hline $\begin{array}{l}00011 \\
6-14-3\end{array}$ & $\mathrm{C} 2 \mathrm{~F} 4$ & $\begin{array}{l}\text { Ethene, } \\
\text { tetrafluoro- }\end{array}$ & & 100.02 & PFOS $(500 ; 49)$ \\
\hline $\begin{array}{l}00035 \\
7-26-6\end{array}$ & C4F8 & $\begin{array}{l}\text { 1-Butene, } \\
1,1,2,3,3,4,4,4 \\
\text {-octafluoro- } \\
\end{array}$ & & 200.03 & PFOS $(300 ; 59)$ \\
\hline \multicolumn{6}{|c|}{ Perfluoroalkanes } \\
\hline $\begin{array}{l}00033 \\
5-57-9\end{array}$ & C7F16 & $\begin{array}{l}\text { Heptane, } \\
\text { hexadecafluor } \\
\text { o- }\end{array}$ & & 388.05 & PFOS $(500 ; 72)$ \\
\hline $\begin{array}{l}00030 \\
7-34-6\end{array}$ & C8F18 & $\begin{array}{l}\text { Perfluoroocta } \\
\text { ne }\end{array}$ & & 438.06 & PFOS $(500 ; 72)$ \\
\hline $\begin{array}{l}00035 \\
5-42-0\end{array}$ & C6F14 & $\begin{array}{l}\text { Hexane, } \\
\text { tetradecafluor } \\
\text { o- }\end{array}$ & & 338.04 & PFOAB $(200 ; 25)$ \\
\hline \multicolumn{6}{|c|}{ Perfluoro aldehyde } \\
\hline $\begin{array}{l}00264 \\
8-47-7\end{array}$ & $\mathrm{C} 5 \mathrm{H} 2 \mathrm{~F} 8 \mathrm{O}$ & $\begin{array}{l}2,2,3,3,4,4,5,5 \\
- \\
\text { Octafluoropen } \\
\text { tanal }\end{array}$ & & 230.06 & $\begin{array}{l}\text { PFOA }(200 ; 59), \text { PFOA }(300 ; \\
36), \text { PFOA }(500 ; 45), \text { PFOA } \\
(890 ; 45)\end{array}$ \\
\hline \multicolumn{6}{|c|}{ Perfluoroalkyl acid } \\
\hline $\begin{array}{l}00033 \\
5-67-1\end{array}$ & $\mathrm{C} 8 \mathrm{HF} 15 \mathrm{O} 2$ & $\begin{array}{l}\text { Pentadecafluo } \\
\text { rooctanoic } \\
\text { acid }\end{array}$ & & 414.07 & PFOA $(200 ; 91)$ \\
\hline \multicolumn{6}{|c|}{ Nonfluorinated compound } \\
\hline $\begin{array}{l}00744 \\
6-09-5\end{array}$ & $\mathrm{O} 2 \mathrm{~S}$ & Sulfur dioxide & $\mathrm{O}=\mathrm{S}=\mathrm{O}$ & 64.06 & PFOS $(890 ; 64)$ \\
\hline
\end{tabular}




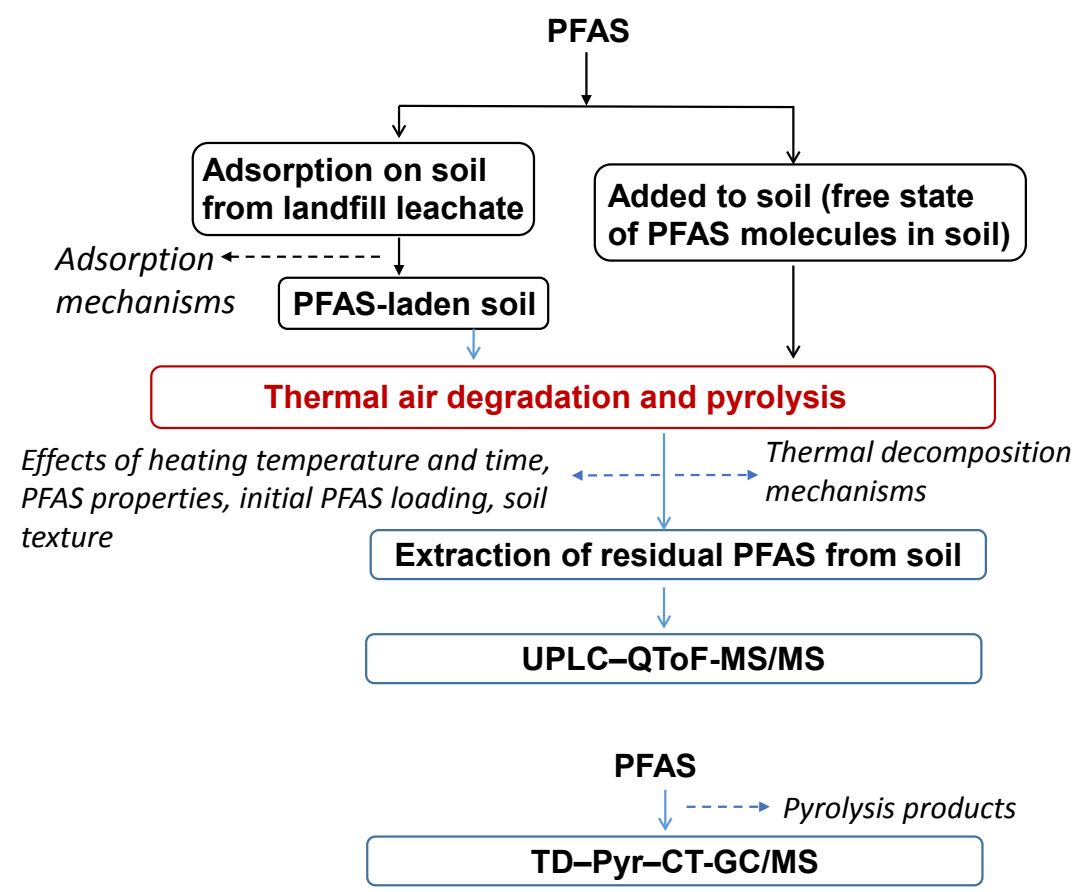

Figure S1. Experimental schematic diagram.

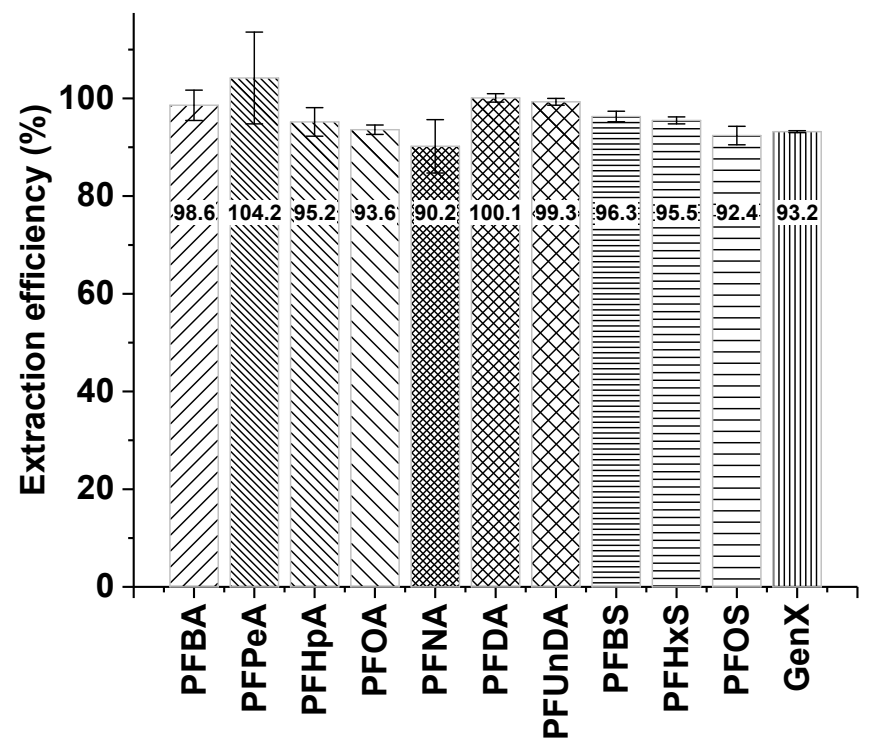

Figure S2. Recovery of PFCAs, PFSAs, and PFECA (i.e., HFPO-DA) from soil using methanol added with $100 \mathrm{mmol} / \mathrm{L}$ ammonium acetate. 

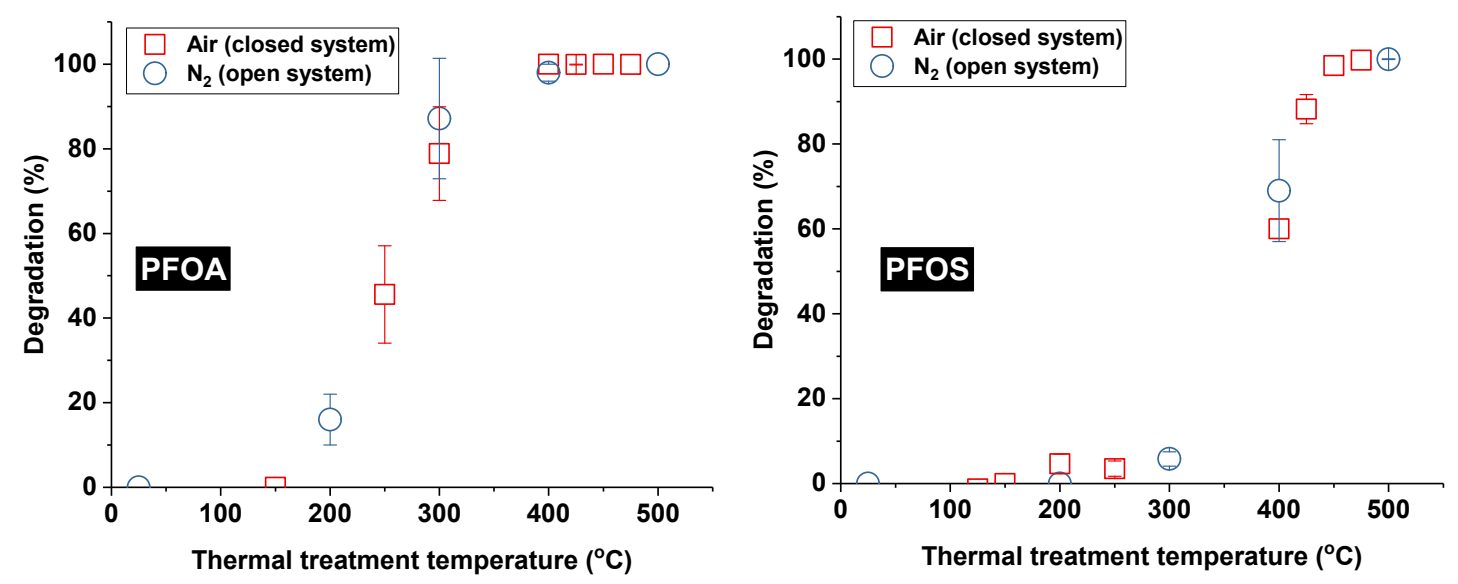

Figure S3. Decomposition of PFOA and PFOS pre-adsorbed in a natural soil after thermally treated for $30 \mathrm{~min}$ at different temperatures under different atmospheres. The heating experiments were performed in a tube furnace under a flow of $\mathrm{N}_{2}$ and in a closed system with air.

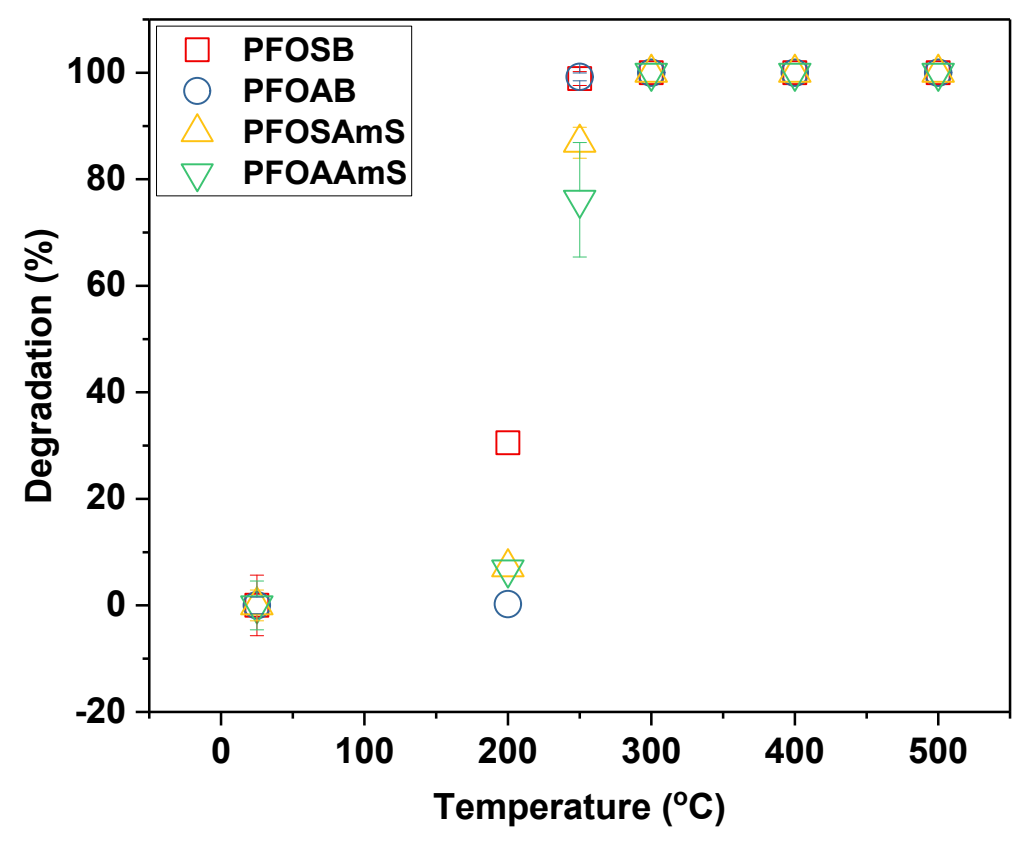

Figure S4. Temperature effect on 30-min thermal decomposition of zwitterionic (PFOSB and PFOAB) and cationic (PFOSAmS and PFOAAmS) along with $0.2 \mathrm{~g}$ of clay (Scenario 2). The experiments were performed in a closed system in an air atmosphere. 

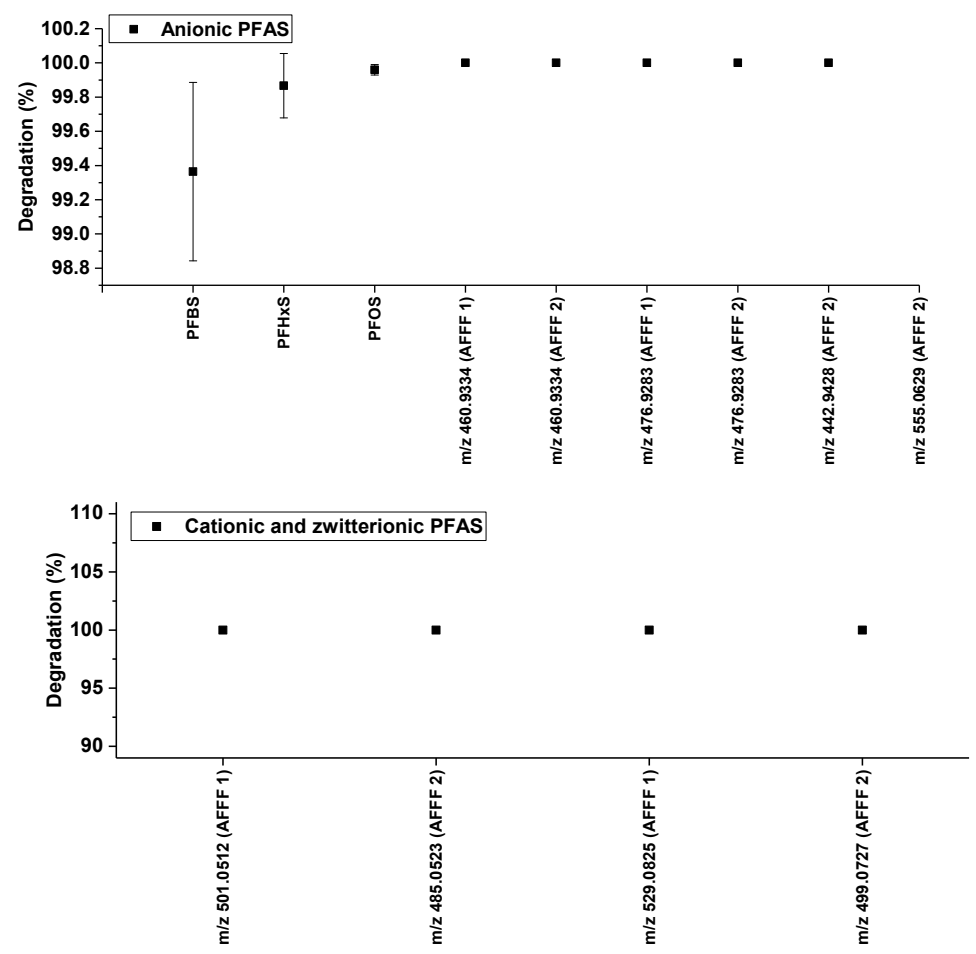

Figure S5. Decomposition of PFSAs and polyfluoroalkyl substances present in AFFF (see Table S2) after 30-min treatment in soil at $500{ }^{\circ} \mathrm{C}$. The decomposition efficiency was assigned to $100 \%$ if no measurable PFAS was found in soil after thermal treatment.

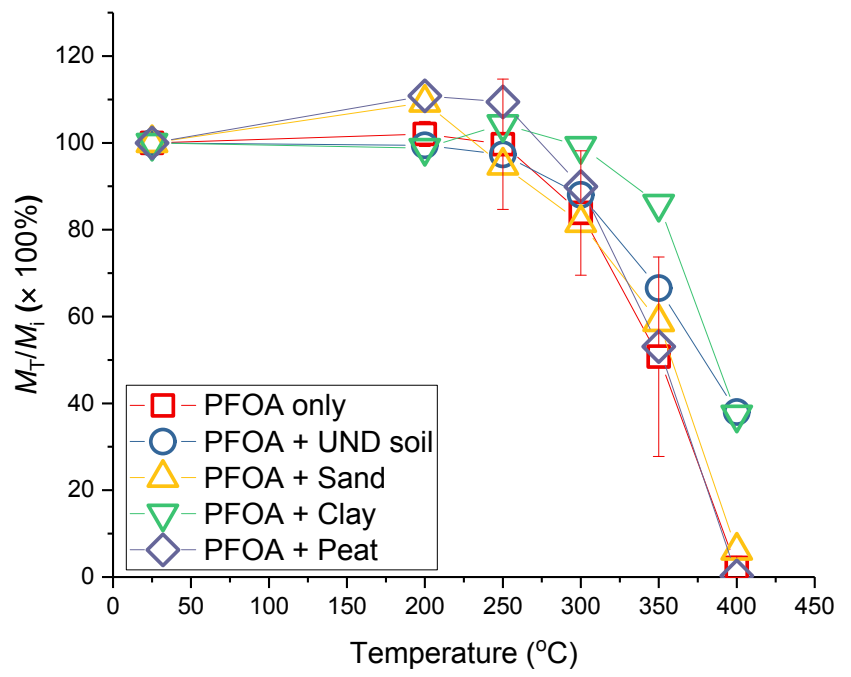

Figure S6. Effect of soil texture on thermal decomposition of PFOA. PFOA powders $(1.2 \times$ $\left.10^{-5} \mathrm{~mol}\right)$ or PFOA $\left(1.2 \times 10^{-5} \mathrm{~mol}\right)$ mixed with soil particles (scenario \#2) were heated from room temperature to a given temperature at $10{ }^{\circ} \mathrm{C} / \mathrm{min} . M_{\mathrm{i}}$ and $M_{\mathrm{T}}$, respectively, refer to the initial mass of PFOA and the residual mass at different temperatures. 


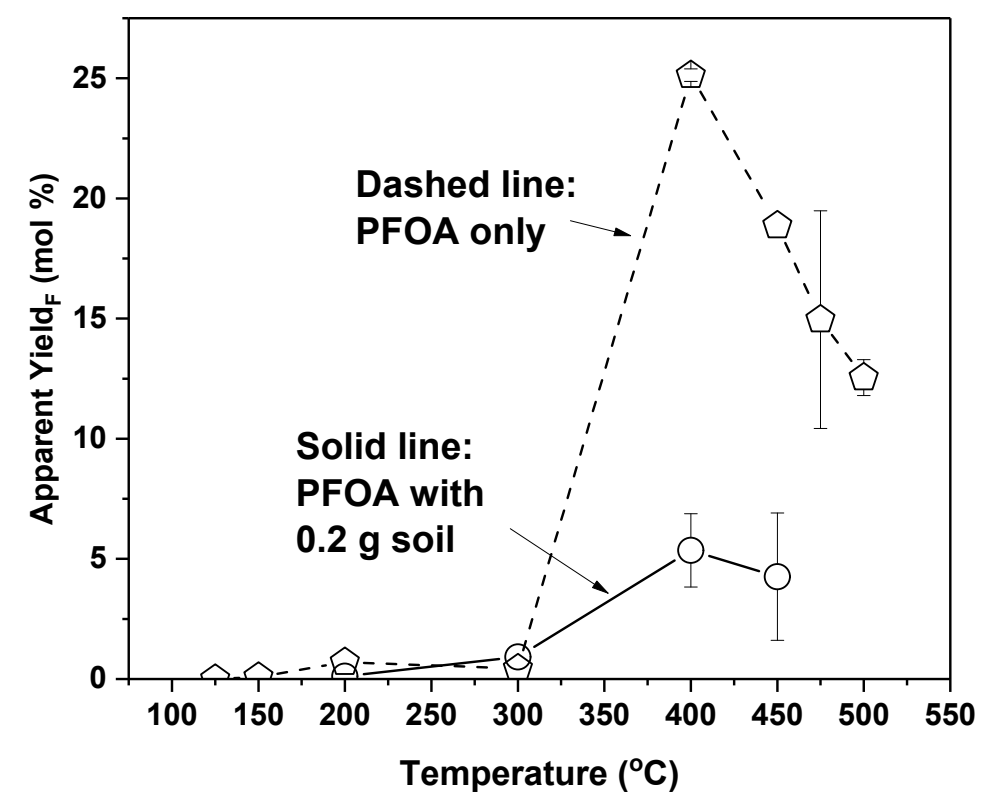

Figure S7. Apparent yield of F from PFOA (initial mass: $1 \mu \mathrm{mol}$ ) heated for $30 \mathrm{~min}$ at different temperatures with or without the presence of a dried natural soil $(0.2 \mathrm{~g})$.

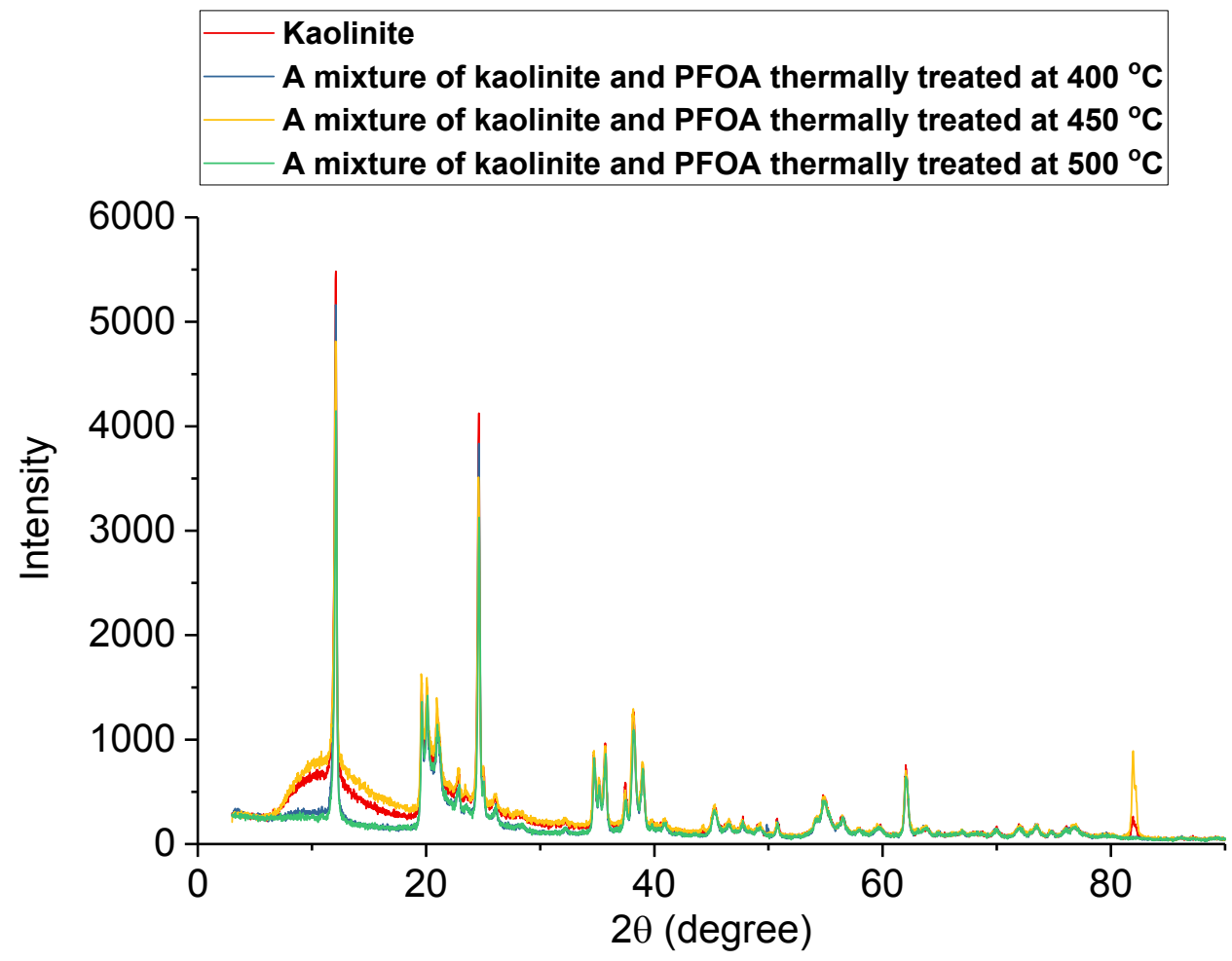

Figure S8. XRD spectra of raw kaolinite $(0.6 \mathrm{~g})$ and a mixture of kaolinite and PFOA (0.005 g) after 30-min thermal treatments at different temperatures. 


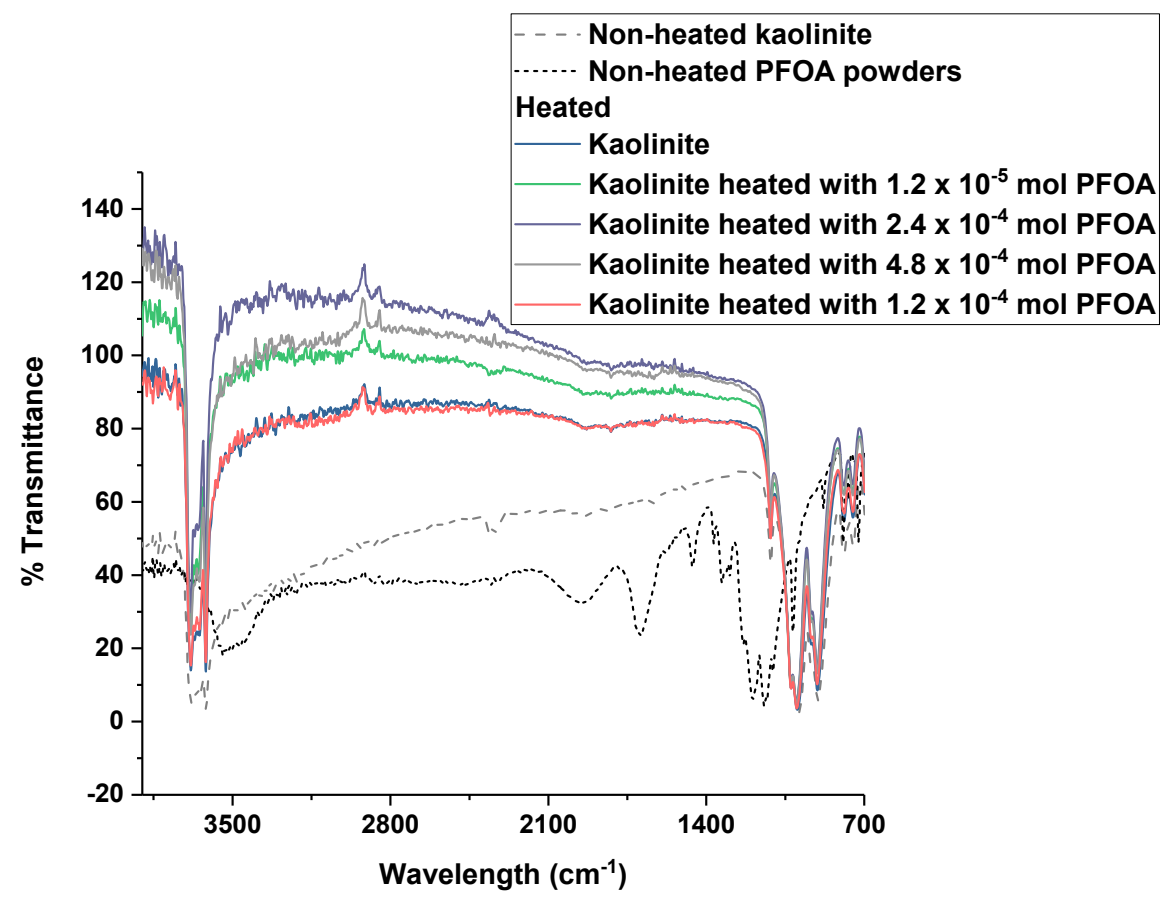

Figure S9. FTIR spectra of non-heated kaolinite, non-heated PFOA powers, and a mixture of kaolinite $(0.2 \mathrm{~g})$ and PFOA $\left(1.2 \times 10^{-5}-1.2 \times 10^{-4} \mathrm{~mol}\right)$ after 30 -min thermal treatment at $400{ }^{\circ} \mathrm{C}$.
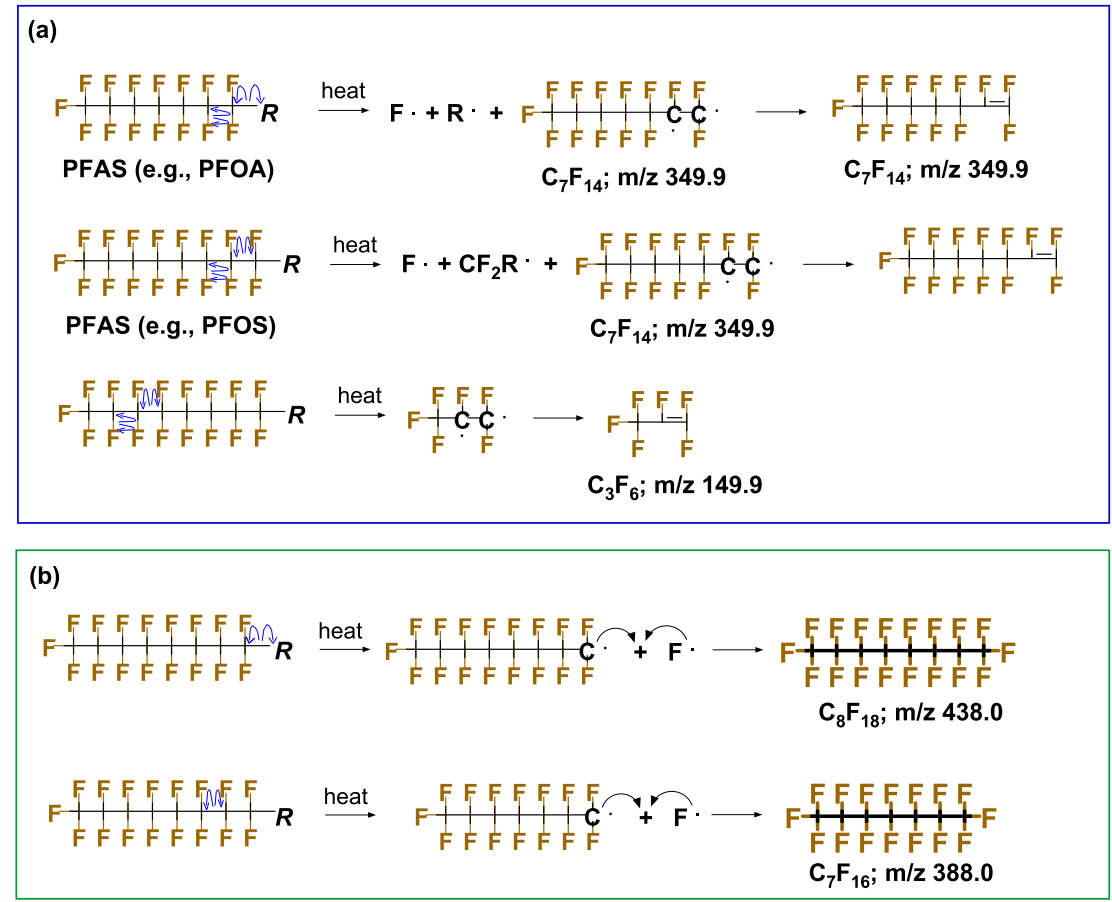

Figure S10. Possible formation pathways of perfluoroalkenes and perfluoroalkanes from PFAS during heating. 


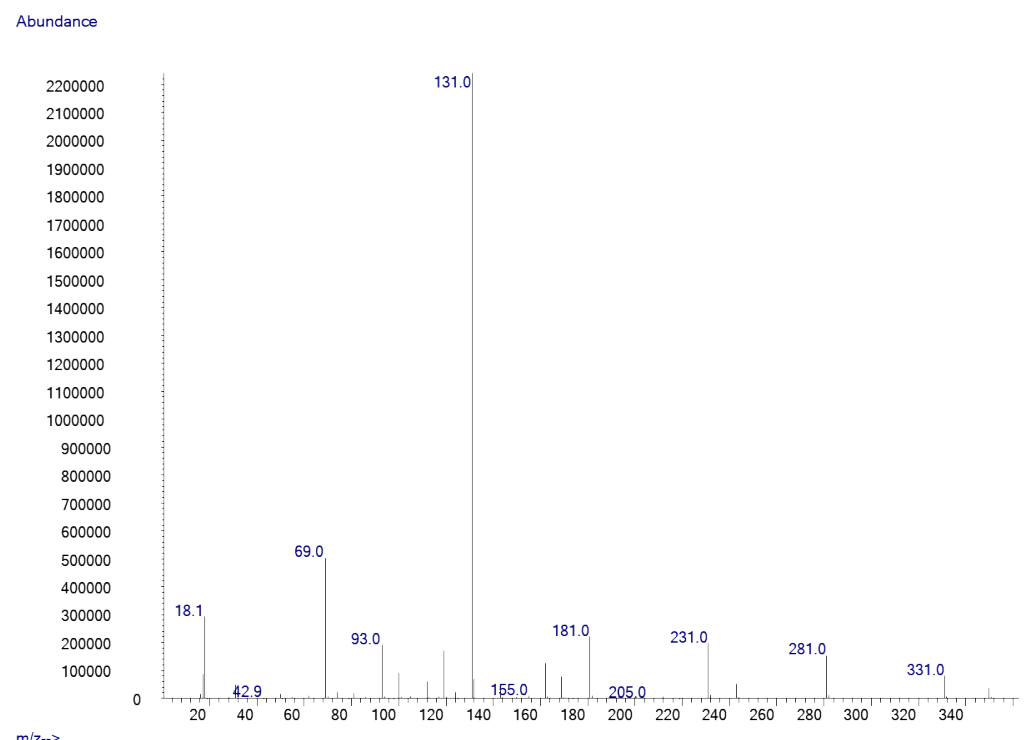

Figure S11. TD-Pyr-CT-GC-MS spectrum of perfluoro-1-heptene (CAS: 755-25-9) generated after heating PFOA at $200{ }^{\circ} \mathrm{C}$.

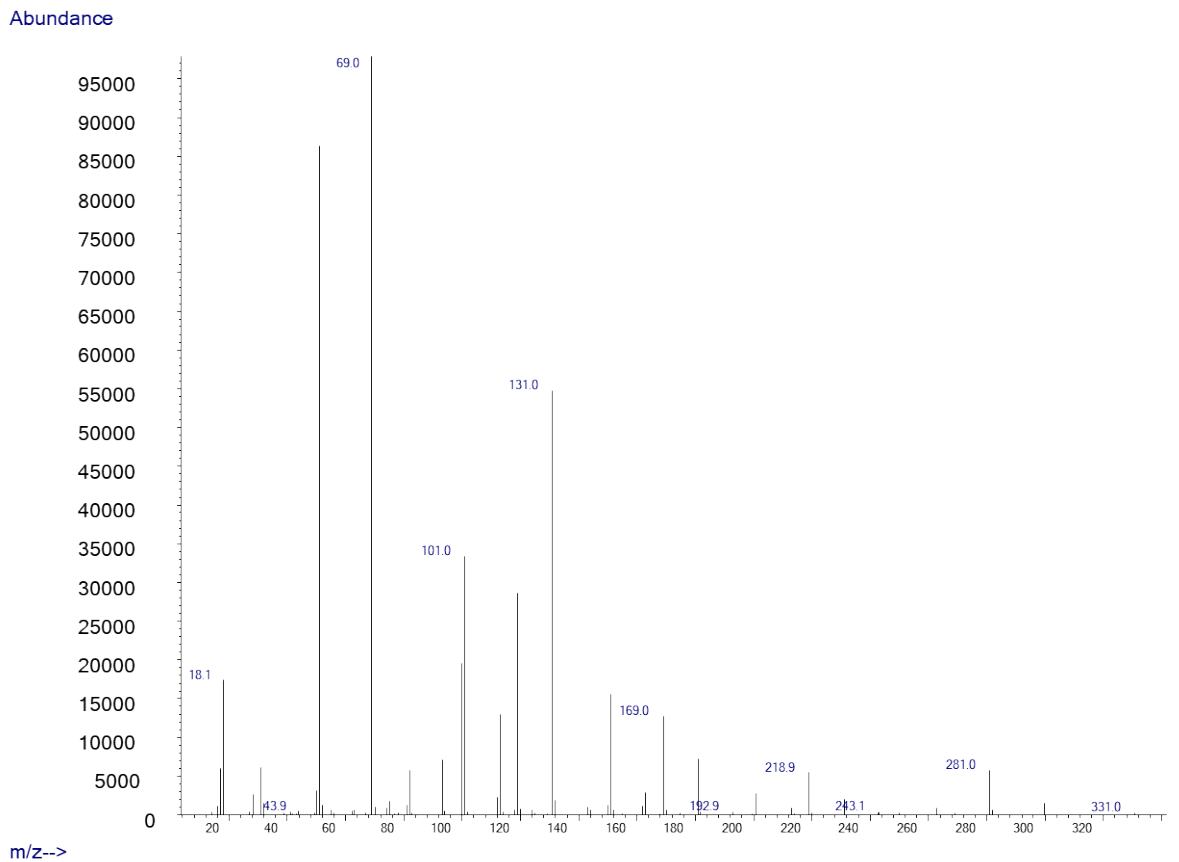

Figure S12. TD-Pyr-CT-GC-MS spectrum of hexane, 1,1,1,2,2,3,3,4,4,5,5,6,6-tridecafluoro(CAS: 355-37-3) generated after heating PFOA at $200{ }^{\circ} \mathrm{C}$. 


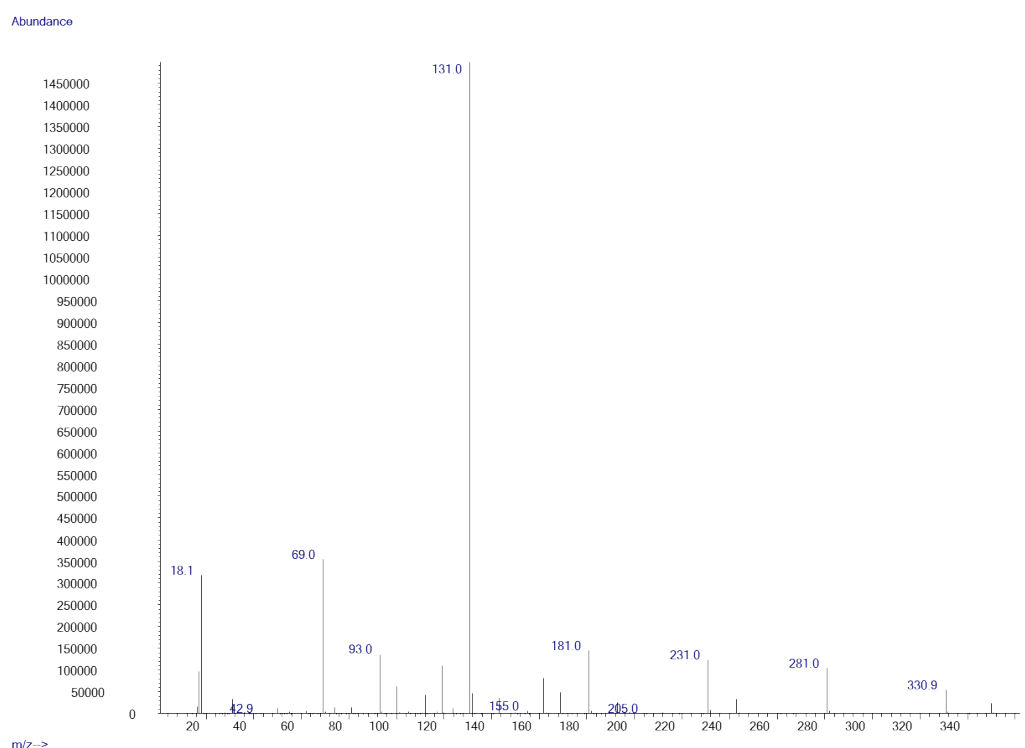

Figure S13. TD-Pyr-CT-GC-MS spectrum of perfluoro-1-heptene (CAS: 755-25-9) generated after heating PFOA at $300{ }^{\circ} \mathrm{C}$.

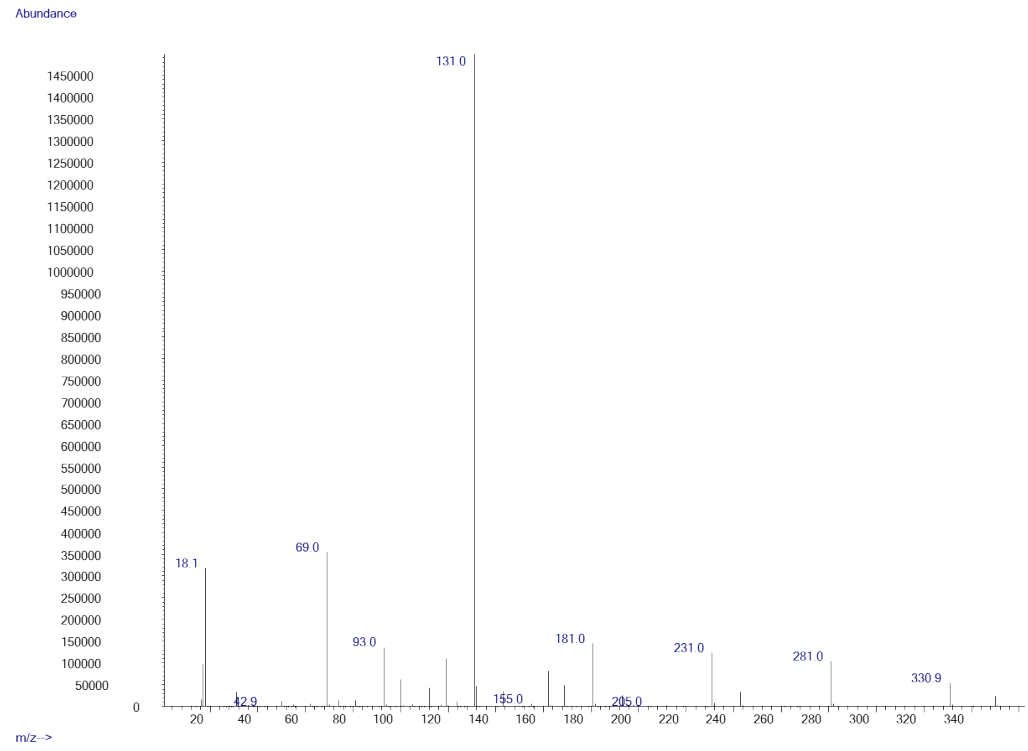

Figure S14. TD-Pyr-CT-GC-MS spectrum of perfluoro-1-heptene (CAS: 755-25-9) generated after heating PFOA at $500{ }^{\circ} \mathrm{C}$. 


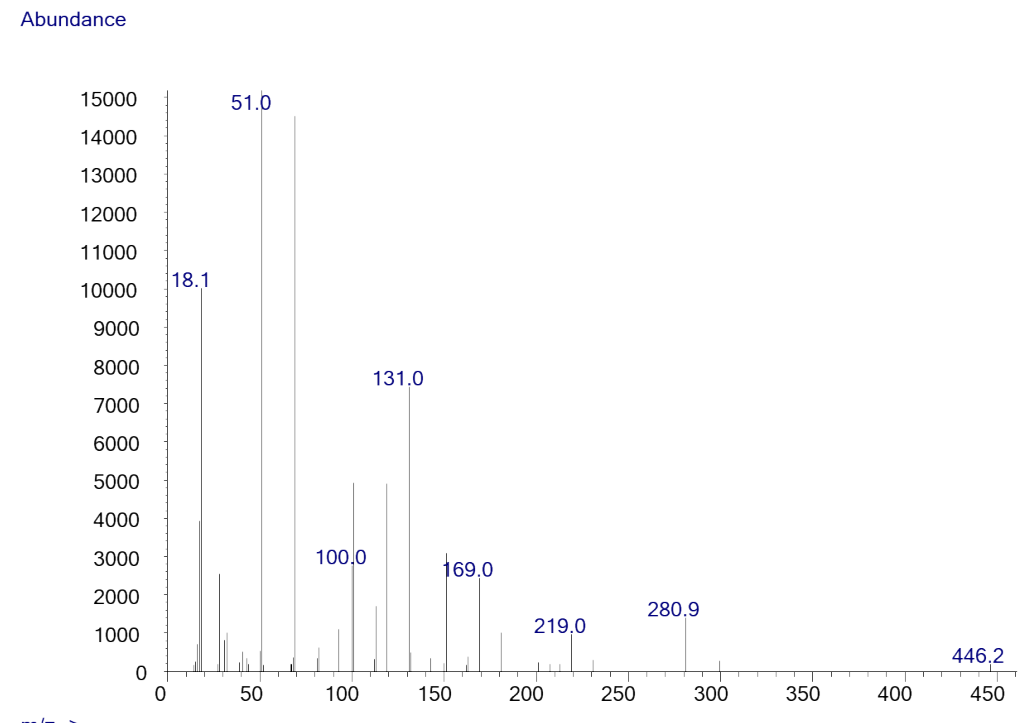

Figure S15. TD-Pyr-CT-GC-MS spectrum of hexane, 1,1,1,2,2,3,3,4,4,5,5,6,6-tridecafluoro(CAS: 355-37-3) generated after heating PFOA at $890{ }^{\circ} \mathrm{C}$.

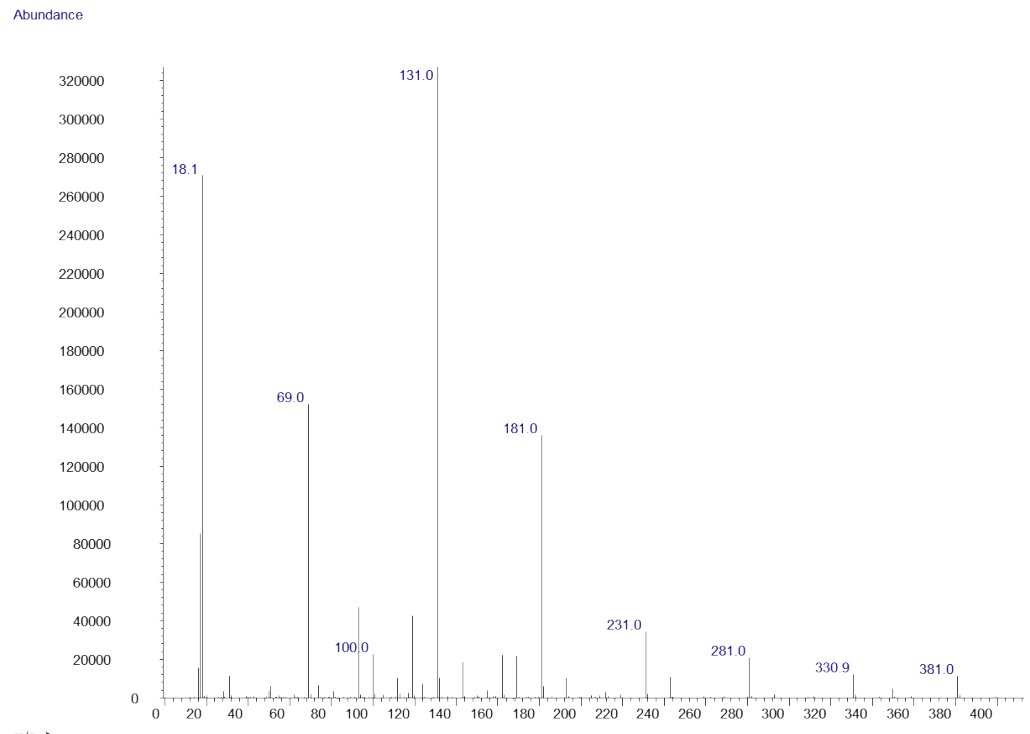

Figure S16. TD-Pyr-CT-GC-MS spectrum of perfluoro-1-heptene (CAS: 755-25-9) generated after heating PFOS at $500{ }^{\circ} \mathrm{C}$. 
Abundance

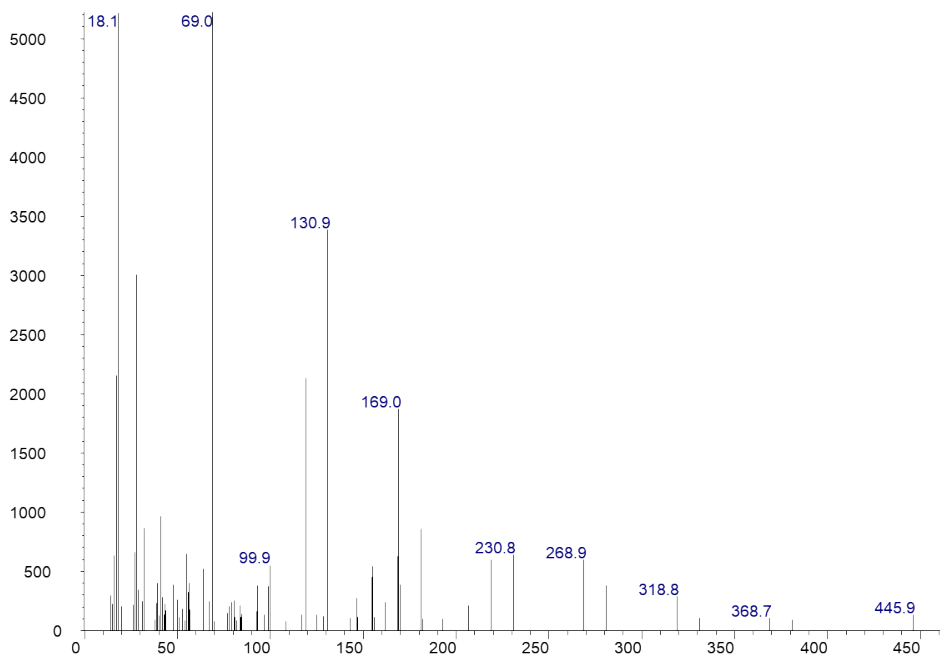

Figure S17. TD-Pyr-CT-GC-MS spectrum of perfluorooctane (CAS: 307-34-6) generated after heating PFOS at $500{ }^{\circ} \mathrm{C}$.

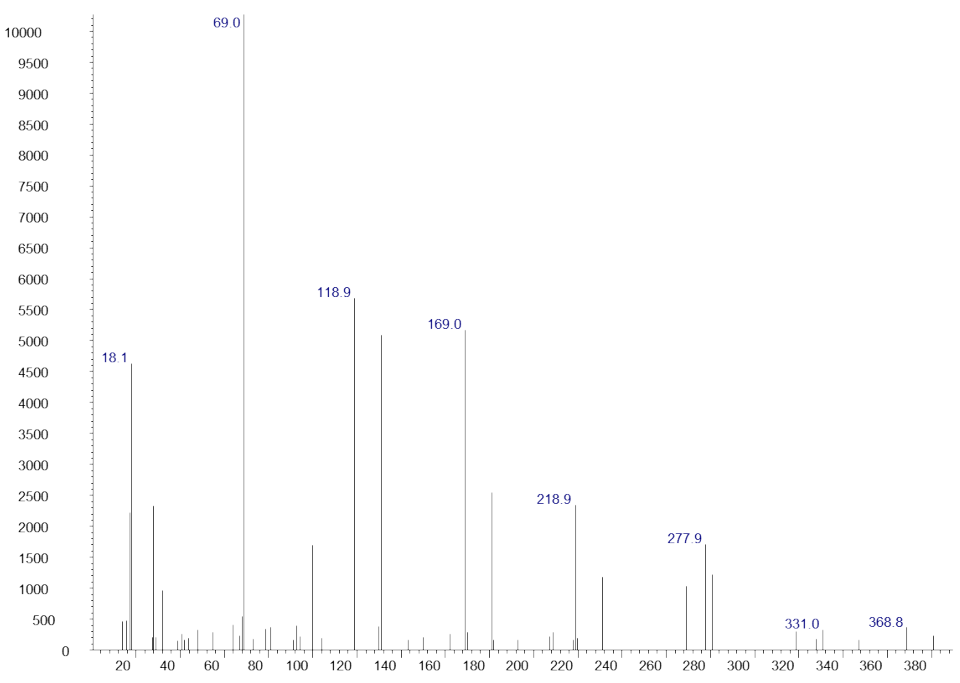

Figure S18. TD-Pyr-CT-GC-MS spectrum of heptane, hexadecafluoro- (CAS: 335-57-9) generated after heating PFOS at $500{ }^{\circ} \mathrm{C}$. 


\section{References cited in the Supporting Information.}

(1) Xiao, F.; Sasi, P. C.; Yao, B.; Kubatova, A.; Golovko, S. A.; Golovko, M. Y.; Soli, D., Thermal stability and decomposition of perfluoroalkyl substances on spent granular activated carbon. Environ Sci Tech Let 2020, 7, 343-350.

(2) Xiao, F.; Hanson, R. A.; Golovko, S. A.; Golovko, M. Y.; Arnold, W. A., PFOA and PFOS are generated from zwitterionic and cationic precursor compounds during water disinfection with chlorine or ozone. Environ Sci Tech Let 2018, 5, 382-388.

(3) Xiao, F.; Golovko, S. A.; Golovko, M. Y., Identification of novel non-ionic, cationic, zwitterionic, and anionic polyfluoroalkyl substances using UPLC-TOF-MS(E) high-resolution parent ion search. Anal Chim Acta 2017, 988, 41-49.

(4) Sasi, P. C.; Alinezhad, A.; Yao, B.; Kubatova, A.; Golovko, S. A.; Golovko, M. Y.; Xiao, F., Effect of granular activated carbon and other porous materials on thermal decomposition of per- and polyfluoroalkyl substances: Mechanisms and implications for water purification. Water Res. 2021, 200, 117271.

(5) Rice, E. W.; Baird, R. B.; Eaton, A. D.; Clesceri, L. S., Standard Methods for the Examination of Water and Wastewater. 22nd ed.; American Public Health Association: Washington, D.C., 2012.

(6) Waters., An overview of the principles of $\mathrm{MS}^{\mathrm{E}}$, the engine that drives MS performance. In Waters Corporation: Milford, MA, 2011; pp 1-6.

(7) Xiao, F.; Sasi, P. C.; Alinezhad, A.; Golovko, S. A.; Golovko, M. Y.; Spoto, A., Thermal decomposition of anionic, awitterionic, and cationic polyfluoroalkyl substances in aqueous filmforming foams. Environ Sci Technol 2021, 55, 9885-9894. 